\title{
They Had Me in Stitches: A Grand Canyon River Guide's Case Report and a Review of Wilderness Wound Management Literature
}

\author{
Susanne J. Spano, MD; Brad Dimock \\ From UCSF-Fresno Medical Education Program, Fresno, CA (Dr Spano); and Arizona Raft Adventures (AzRA), Flagstaff, AZ (Mr Dimock).
}

\begin{abstract}
We present a case of failed conservative management of a traumatic wound sustained in a wilderness setting. The patient was initially treated with a povidone-iodine scrub, suture closure, and expectant management by 2 physicians who were paying clients on a multiday river rafting expedition. Empiric antibiotic coverage and irrigation of the dehisced wound were initiated several days after initial treatment. The patient arranged his own evacuation 8 days after injury. Hospitalization, intravenous (IV) antibiotics, and surgical debridement with wound vacuum placement led to a full recovery. This case presents several common wound care pitfalls. The sequelae to these pitfalls are more dramatic in a wilderness setting and underscore the importance of early aggressive management and considering prompt evacuation when treating wounds sustained in the wilderness.
\end{abstract}

Key words: wound management, wilderness medicine, laceration repair, wound infection, prophylactic antibiotics

\section{Introduction}

More than 250 million persons visited a national park within the United States in 2012, which meets and exceeds previous attendance records while simultaneously raising the likelihood for potential injuries sustained in wilderness settings. ${ }^{1}$ Acute traumatic wounds are common, consistently ranking in the top 10 reasons for emergency room visits for adult males and all pediatric patients under the age of $15 .^{2}$ In wilderness settings, lower extremity musculoskeletal trauma has been reported to constitute up to half of all injuries sustained. ${ }^{3}$ A comprehensive approach to acute wound care is important in the hospital-based setting, but is especially critical in the wilderness setting, as definitive treatment can be hours to weeks away. The limitation of available medical resources and the variety of acute traumatic wounds present a challenge. Each wound needs individual evaluation to minimize complications of poor wound healing, infection, and long-term functional deficits.

We present a case from the Grand Canyon that illustrates how these factors can come into play with what initially seems like an uncomplicated wound

Corresponding author: Susanne J. Spano, MD, 155 N. Fresno Street, Suite 206, Fresno, CA 93701 (e-mail: sspano@gmail.com). closure and conservative management strategy. The following narrative comes from Brad Dimock, a veteran Grand Canyon river guide for more than 30 years, whose last season sent him to the operating room twice. Brad Dimock is a legend as a Colorado River boatman, one of very few to have rafted the River at almost $100,000 \mathrm{ft}^{3} / \mathrm{s}$ in the infamous Glen Canyon Dam flood of 1983, which was and still is the highest water flow recorded there since early construction work at the Glen Canyon Dam site in 1958. ${ }^{4}$ Record-breaking precipitation in 1983 resulted in Lake Powell reaching its highest recorded level in history and the only time the spillways of Glen Canyon Dam have been opened for floodwater management. ${ }^{5}$ Brad's knowledge of the Colorado River is encyclopedic. He is also a historian and author of several prize-winning books on rafting and the Colorado River, as well as a publisher and President of Fretwater Press. Dimock's style shies away from pedantic relating of facts as he views every subject as another avenue for his greatest talent, storytelling. This case report is his firsthand account.

\section{Case Report}

Day 1 (Day 6 of the trip, but Day 1 of the injury). We are at Bright Angel Trail at Pipe Creek with a big exchange. 
River trips in the Grand Canyon can take from 2.5 to 5 weeks from Lee's Ferry at river mile 0 to South Cove, Lake Mead, at river mile 297 (Figure 1). ${ }^{6}$ One can shorten their trip by hiking in or out mid-route, which is called an "exchange." The new passengers have all arrived early, and we are hustling to get things rolling and capitalize on the mileage we can make. I hop onto my raft to grab a water jug and slip off the wet, slippery tube. My foot bounces across a couple of loose duffle bags in my bilge, and my shin slams into the frame. "Ow!" says I, thinking, That really hurt. This might draw blood. I pull my leg out and am stunned and horrified to see a 4-inch gash to the shinbone, spreading open, gushing blood. I force the gaping wound closed with my hands and hobble to my seat. It's a big wound; I need help (Figure 2).

We have a quick group discussion to decide who should do the cleansing and Steri-Stripping. The bleeding has stopped, but it is yucky looking. Just as we begin, one of our incoming hikers introduces himself as an orthopedic surgeon and offers to help. His friend, an anesthesiologist, offers a full suture kit with lidocaine (Figure 3). They both feel that stitches are really the way to deal with a wound of this magnitude since Steri-Strips are not likely to hold (Figure 4). I defer to their experience and choose to have them handle the situation. They seem competent, intelligent, and optimistic. Six widely spaced sutures are placed after I had shaved my leg (Figure 5). It is then wrapped up with a $3 \mathrm{M}$ Tegaderm transparent waterproof dressing, with a $3 \mathrm{M}$ Coban self-adherent wrap to protect it. We all think this looks great and prepare to depart. In all, we don't lose more than a few minutes. There is no dissent on the decision to carry on.

We run the rafts all the way to river mile 104. There we pull the Tegaderm, change to a clean, dry dressing for the night, and celebrate. In the morning, we replenish with a new dry dressing, fresh Tegaderm, and a wrap. This goes on for a couple days and it still looks great. We're all feeling we are doing the right thing.

Night 5. We are 4 days in, and the wound starts looking a little angry and red (Figure 6). The anesthesiologist and orthopedic surgeon start me on trimethoprim/ sulfamethoxazole.

Day 6. I rest in the shade while the folks go to Whispering Springs. We still feel like this thing is totally going to be fine.

Day 7. I harbormaster for the day at Havasu Creek and watch the red area on my shin creep past the Sharpie lines we drew around it the night before. A nurse on the trip takes a look at it and cringes diplomatically when I tell him we're probably going to hit it with bigger antibiotics tonight and see what happens. His doubt is contagious and escalates mine. My ankle is a cankle. The wound is heating up. When a finger is pushed into my shin, the dent stays there. I want to talk it over with the docs, but they are at Upper Beaver Falls. I am not panicking, not yet.

The folks get back too late to do an evacuation the same day, and we blast down to a ledge camp at river mile 162 . My medical team (the anesthesiologist and orthopedic surgeon) shares my fears. It's beyond what we want to, or should be, dealing with on the river. It's heading south on

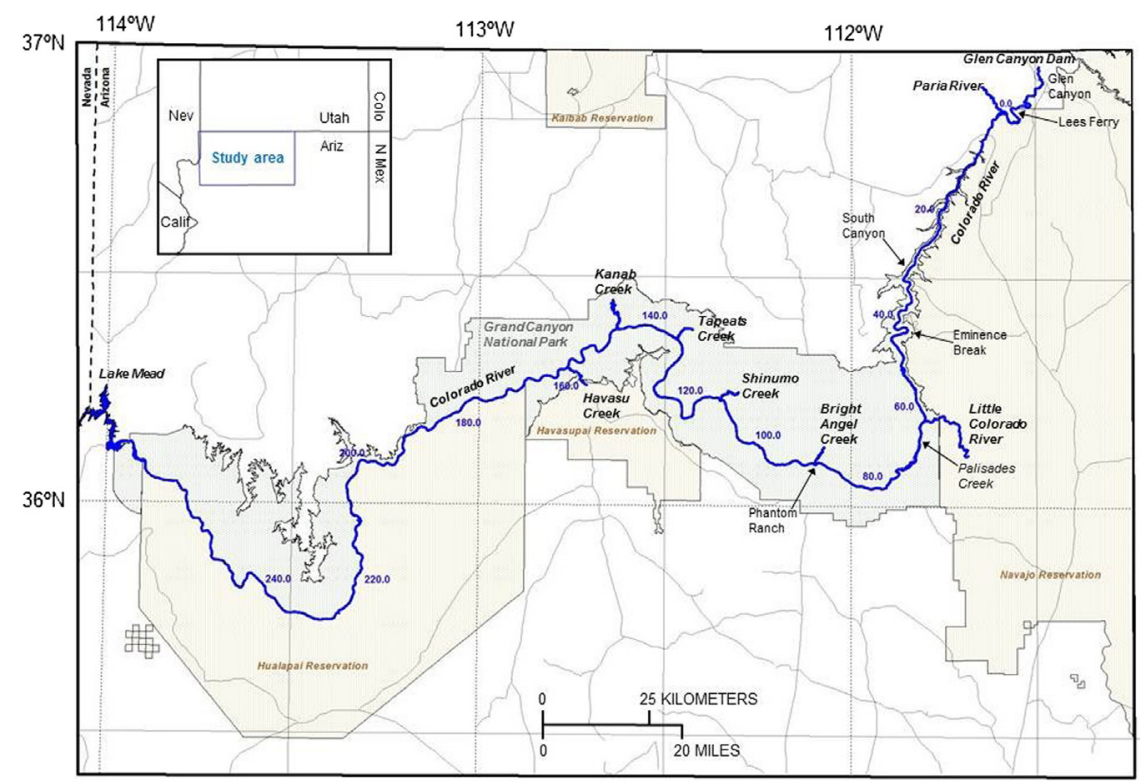

Figure 1. The route of the Colorado River through Grand Canyon National Park. ${ }^{6}$ 


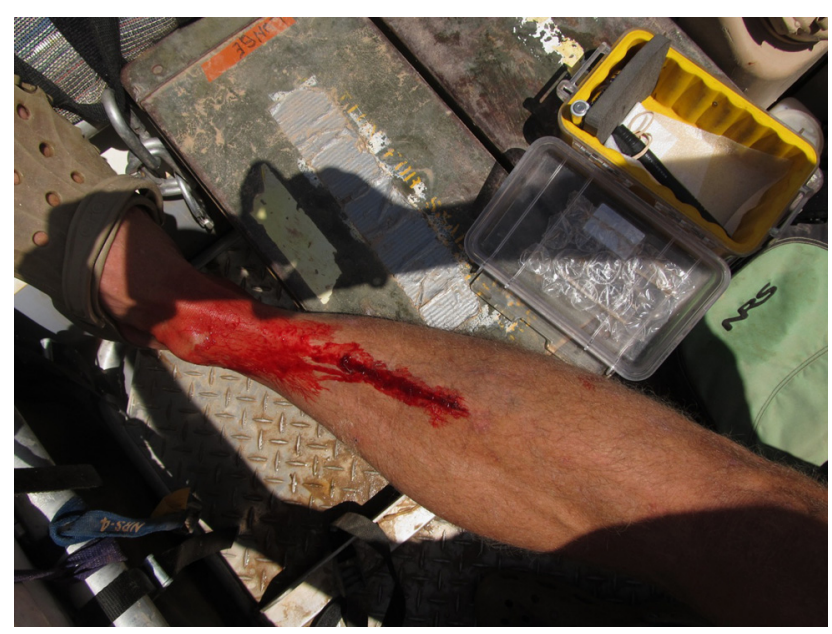

Figure 2. Initial injury.

us. Since we can't fly at night, they elect to cut stitches, reopen the wound, drain it, wash it, and pack it with povidone-iodine-impregnated gauze. For this surgery, I am instructed to do my own anesthesia-I opt for gin and tonic. GIN and tonic. For douching the wound clean, we use my Flash Gordon squirt gun filled with povidoneiodine solution (Figure 7). It has a far more powerful blast than a syringe. I grimace, laugh, yelp, clench, take pictures, and administer more anesthesia. It's clean now, but I don't even like my steaks to look as cooked as my lower leg does (Figure 8). We begin a second layer of antibiotics, azithromycin, in addition to the trimethoprim/sulfamethoxazole. I feel physically healthy, but the pain and heat in my shin has me terrified. We prepare to launch at first light with the assistants to go find a good southeast window for satellite phone connection and set up the evacuation. All things considered, it's a good plan.
But I toss and turn a lot for much of the night, wretched, scared, and thinking of all the wounds-gonebad stories I know. The months-in-the-hospital stories. The infection-that-just-won't-stop stories. The loss-ofleg stories. I want to go home really, really bad.

Day 8, 5:35 AM. River mile 163. Contact by satellite phone is made with the National Park Service rangers. A 10:00 AM rendezvous at National helipad is confirmed. I've set up a lot of evacuations in my day, but it's truly weird to be setting up my own. It's a 45-minute helicopter flight to the South Rim of the Grand Canyon with a 1.5-hour drive to Flagstaff from there. At noon I am sitting in a truck with a Big Mac heading for Flagstaff. I enjoy a short-lived optimism.

2 PM. The hospital-based surgeon takes a look, shakes his head, tells me this wound may no longer be closable at this late date, and this may entail a long recovery. The inflammation has reduced a bit, but it looks like hell. I am really, really sad now. It's been a week since I whacked

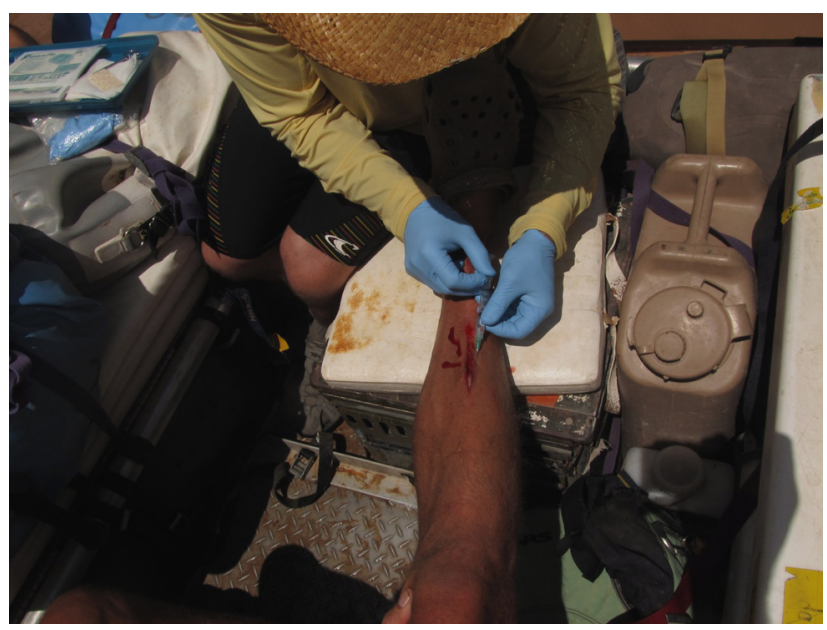

Figure 3. Numbing the wound with lidocaine. 


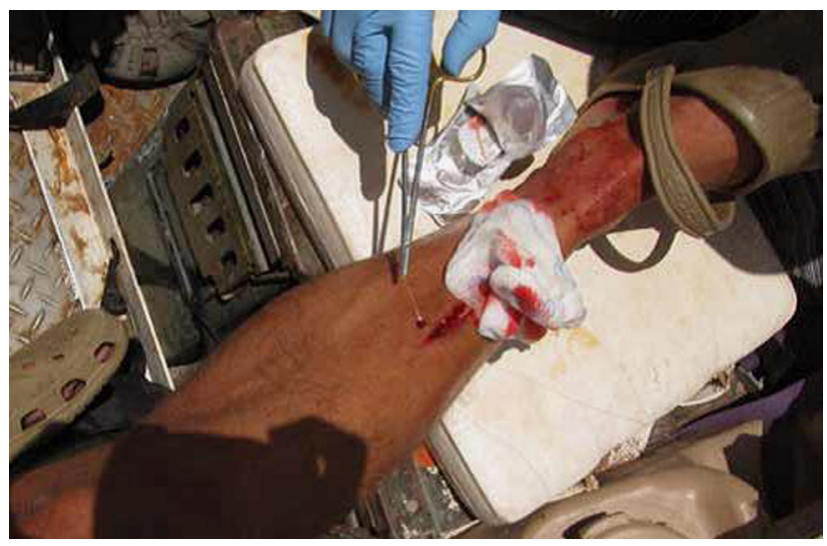

Figure 4. Suturing the wound in the boat.

my shin, and things are majorly screwed up. At 9 PM I am in the operating room (OR). I awake with a wound-vacuum in place, antibiotics, and a wacky thing around my other calf that periodically inflates and squeezes the fluids from my lower leg like an anaconda that occasionally wakes up, flexes around my leg affectionately, and goes back to sleep.

Day 9. I stare at San Francisco Peak out my window. Nice people come to visit me. The wound vacuum keeps gurgling away, the IV keeps dripping, the anaconda keeps snuggling me.

Day 10, noon. Back to the OR. The tissue is healthy (Figure 9). The wound is closed with new stitches, and I am sent home with antibiotics. Days later I see a very happy shin, no redness, no swelling, no heat, and no cankle below (Figure 10). You have no idea how happy I am.

\section{Discussion}

In summary, the presented case is of a healthy male without any known risks for suboptimal wound healing such as smoking, diabetes, or advanced age. His wound was not initially irrigated before closure, but was externally scrubbed with povidone-iodine solution and the leg was shaved. The providers immediately opted for wound closure given the size of the laceration, the personal supplies they had brought, and preexisting expertise with closing wounds in an operative setting. Leaving the wound open was not discussed. The antibiotic choices were made based on the clinical judgment and available resources of the treating providers, and the clinical rationale is not available as the treating field physicians did not coauthor this report. This case brings up the need to have a systematic approach to evaluating injuries and managing the course of wilderness wounds.

Principles of wound management in the wilderness are similar to that of hospital-based management, with the exceptions of evaluating wound appropriateness for closure and often dealing with limited resources for acute wound care. ${ }^{7}$ The objectives of this article are to reinforce a systematic approach to wound assessment, review

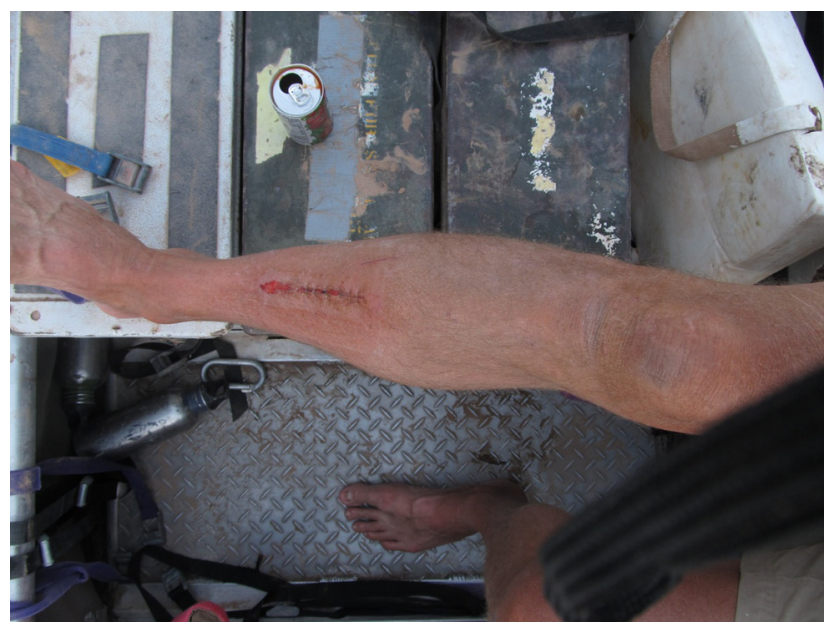

Figure 5. Final suture repair on day 1. 


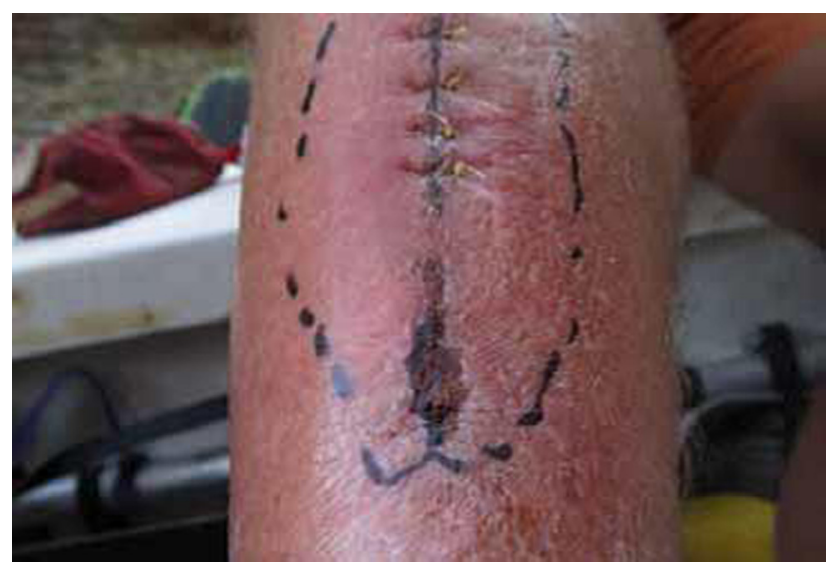

Figure 6. Wound infection on day 5.

evidence-based common pitfalls in provider care, and apply those lessons to the case reported. This review of the current literature will aid the wilderness medicine provider in maintaining a heightened vigilance for what may initially appear to be a minor or uncomplicated injury.

A 2010 wound management review article reviewed common pitfalls in hospital-based emergency management of wounds. ${ }^{8}$ Several errors identified by the authors also impact wilderness wound management. These include failing to provide adequate patient education regarding wound care, use of excessive irrigation (pressure and volume) for clean wounds or for wounds in highly vascularized regions, and irrigation with tissuetoxic solutions such as povidone-iodine, chlorhexidine, or hydrogen peroxide, which can hamper acute wound healing. ${ }^{9}$ As seen in this case, 2 competent physicians translated their common practices in the operating suite erroneously to the wilderness setting. Shaving the skin, high-pressure irrigation, and use of povidone-iodine are practical preoperatively for intact skin, but each can be detrimental to wound health in already injured tissue.
Optimal wound management entails appropriate initial irrigation as well as providing a moist wound environment. Occlusive dressings have lower infection rates than conventional dressings, ${ }^{10}$ and moist wound environments accelerate wound healing by up to $50 \%$ compared with exposure to air. ${ }^{11}$ The prehospital providers choose an ideal wound dressing by using a 3M Tegaderm transparent waterproof dressing. This type of wound covering not only keeps a moist environment for optimal wound healing and prevents superinfecting organisms from contaminating the wound, but also allows for visual inspection of the wound without removal because of the transparent nature of the adhesive dressing. However, the treating providers may not have recognized that the wound was contaminated at the moment of insult by the surrounding river water. The only water considered clean, from a wound standpoint, would be water that is potable. This encompasses filtered, boiled, or chemically treated water. Irrigation of wounds with clean water sources can be appropriately managed with manually compressing premanufactured

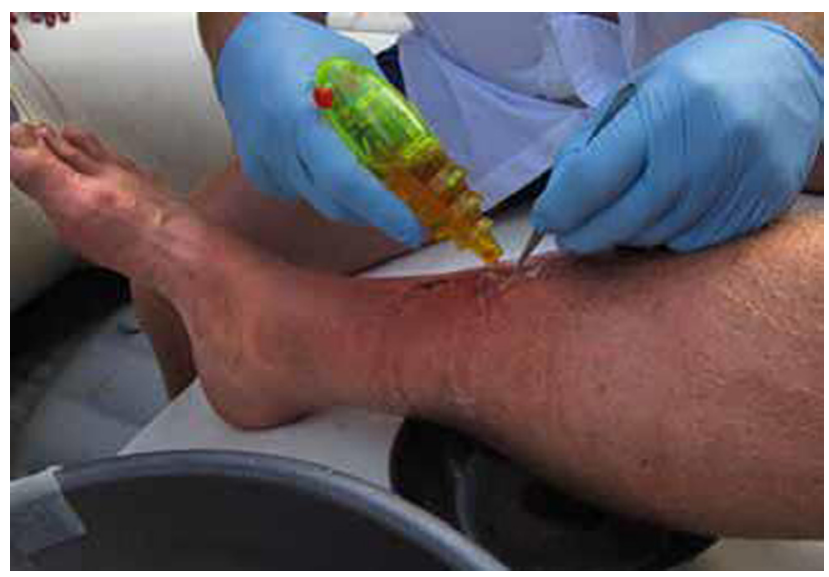

Figure 7. Wound irrigation on day 7. 


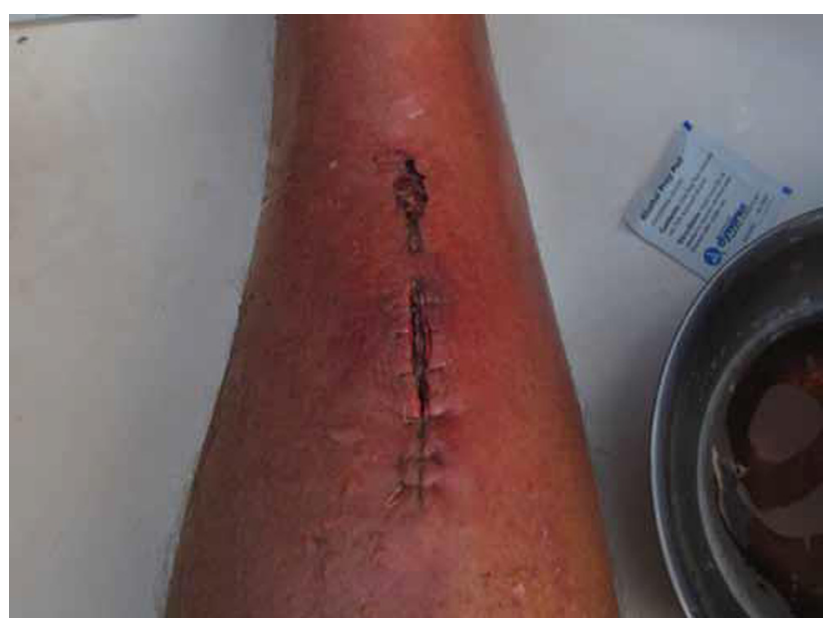

Figure 8. Wound immediately after irrigation.

1-L irrigation bottles, or with a $10-$ to $20-\mathrm{mL}$ syringe depressed to express clean irrigation solution. Research on the effectiveness of improvised irrigation devices has not yet been published.

Freshwater environments are habitats for several Gram-positive species including the coryneform group and Bacillus species. ${ }^{12}$ Wounds sustained in this setting require Gram-positive antibiotic coverage. ${ }^{13}$ Freshwater sources are also a host to many Gram-negative species of bacteria, most notably Aeromonas, which is relatively resistant to a wide variety of antimicrobials including trimethoprim, cefazolin, and ampicillin. ${ }^{12}$ Although rare, Aeromonas colonization is more common with penetrating injuries and also should be suspected in rapidly progressing infections. ${ }^{14}$ The majority of freshwatercontaminated wounds respond to oral courses of levofloxacin and trimethoprim/sulfamethoxazole. ${ }^{14,15}$ If an Aeromonas infection is clinically suggested, one should arrange for prompt initiation of broad-spectrum IV antibiotics and appropriate surgical care. ${ }^{15}$ If this wound had been categorized as a "contaminated wound" on initial examination by the treating providers, the commencement of prophylactic antibiotics on the day of injury would have been reflexive.

Uncomplicated wounds less than $2 \mathrm{~cm}$ (just under 1 inch) have been shown to have comparable cosmetic and infection rates whether or not sutured closure is used. ${ }^{16}$ Clearly this wound was larger, and loose approximation was arguably a reasonable choice. There is a paucity of literature to support a preferred closure technique for wounds sustained in wilderness settings. Tissue glues, either Federal Drug Administration-approved or commercial cyanoacrylate glues, can be used in a relatively safe and efficacious manner in minor trauma. ${ }^{17}$ Adhesive strips have been shown to have similar rates of infection, wound dehiscence, and cosmetic results as sutures, but

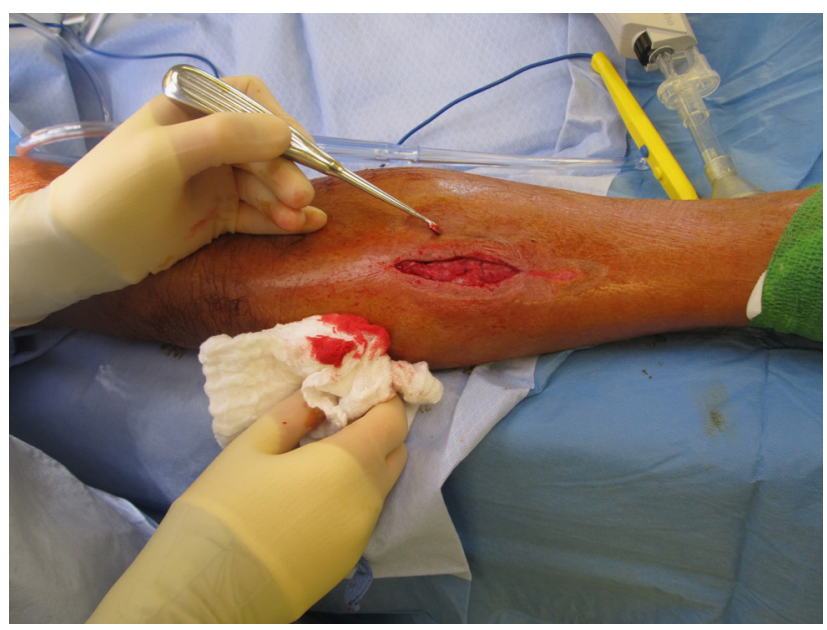

Figure 9. Wound in the operating room on day 10 . 


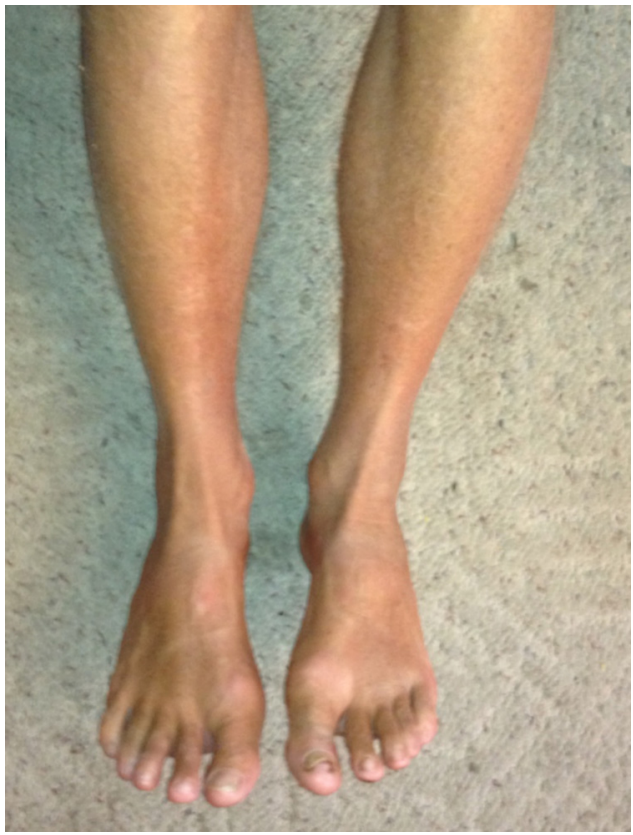

Figure 10. Wound healed (more than 1 year after injury).

have only been systematically compared in small surgical wounds. ${ }^{18}$ It is the opinion of the first author that large or high-tension wounds with controlled hemostasis be managed with wet-to-dry dressings and delayed closure. Wounds that require intervention for hemostasis can be sutured, with the provider maintaining a low threshold for evacuation for definitive management. Further study on optimal wound closure in wilderness settings is warranted. The common pitfalls in wound care exemplified by this case stress the point that providers need to dedicate most of their attention to determining whether a wound is truly uncomplicated or not, and then act accordingly given the available resources and the wound environment.

\section{Conclusions}

We present a case of a wound sustained in an unclean environment with a delay in empiric antibiotics and evacuation. Providers should consider the potential pitfalls of applying their standard of care routines to wilderness environments, as their knowledge and scope of practice may not translate directly to field practice. Environmentspecific microbial considerations as well as limited access to definitive care if wound healing does not proceed as anticipated must be considered in even apparent minor trauma. Wound care principles that were not initially addressed include initial irrigation of the wound and appropriate prophylactic antibiotics at the onset of injury. Further research in wilderness medicine regarding wound appropriateness for closure is warranted.

\section{References}

1. Repanshek K. National Park visitation in 2012 rose to nearly 283 million. National Parks Traveler. Online 15 February 2013. Available at: http://www.nationalparkstraveler.com/ 2013/02/national-park-visitation-2012-rose-nearly-283-mil lion22827. Accessed November 22, 2013.

2. The National Ambulatory Medical Care Survey: 2008 Emergency Department summary tables. 2011. Available at: http://www.cdc.gov/nchs/data/ahcd/nhamcs_emergency/ 2008_ed_web_tables.pdf. Accessed November 22, 2013.

3. Ela GK. Epidemiology of wilderness search and rescue in New Hampshire, 1999-2001. Wilderness Environ Med. 2004;15:11-17.

4. National Water Information System, US Geological Survey. Peak streamflow for the nation: USGS09380000 Colorado River at Lee's Ferry, AZ. Available at: http:// nwis.waterdata.usgs.gov/nwis/peak?site_no $=09380000$ \&agency_cd=USGS\&format=html. Accessed November 22, 2013.

5. Wolf TJ. The Bureau showed the Right Stuff: how Lake Powell almost broke free of Glen Canyon Dam this summer. High Country News. 1983;15(22):10-14.

6. Davis PA. Natural-color and color-infrared image mosaics of the Colorado River corridor in Arizona derived from the May 2009 airborne image collection. US Geological Survey, Data Series 780. Available at: http://pubs.usgs. gov/ds/780/. Accessed September 18, 2013.

7. Joslin J, Auerbach P. Laceration repair in the wilderness. 2008. Available at: http://www.healthline.com/healthblogs/outdoor-medicine/laceration-repair-wilderness. Accessed November 22, 2013.

8. Nicks BA, Ayello EA, Woo K, Nitzki-George D, Sibbald RG. Acute wound management: revisiting the approach to assessment, irrigation, and closure considerations. Int $J$ Emerg Med. 2010;3:399-407.

9. Rodeheaver GT, Ratliff C. Wound cleansing, wound irrigation, wound disinfection. In: Krasner DL, Rodeheaver GT, Sibbald RG, Woo KY, eds. Chronic Wound Care. 4th ed. Malvern, PA: HMP Communications; 2008.

10. Hutchinson JJ, Lawrence JC. Wound infection under occlusive dressings. J Hosp Infect. 1991;17:83-94.

11. Fonder MA, Mamelak AJ, Lazarus GS, Chanmugam A. Occlusive wound dressings in emergency medicine and acute care. Emerg Med Clin North Am. 2007;25: 235-242.

12. Auerbach PS, Yajko DM, Nassos PS, Kizer KW, Morris JA Jr, Hadley WK. Bacteriology of the freshwater environment: implications for clinical therapy. Ann Emerg Med. 1987;16: 1016-1022.

13. Noonburg GE. Management of extremity trauma and related infections occurring in the aquatic environment. J Am Acad Orthop Surg. 2005;13:243-253.

14. Semel JD, Trenholme G. Aeromonas hydrophilia waterassociated traumatic wound infections: a review. J Trauma. 1990;30:324-327. 
15. Beckert BW, Puckett CL, Concannon MJ. Analysis of freshwater pathogens: a guide to rational empiric antibiotic coverage. Mo Med. 2004;101:219-221.

16. Al-Nammari SS, Quyn AJ. Towards evidence based emergency medicine: best BETs from the Manchester Royal Infirmary. Conservative management or suturing for small, uncomplicated hand wounds. Emerg Med J. 2007;24:217-218.
17. Davis KP, Derlet RW. Cyanoacrylate glues for wilderness and remote travel medical care. Wilderness Environ Med. 2013;24:67-74.

18. Gkegkes ID, Mavros MN, Alexiou VG, Peppas G, Athanasiou S, Falagas ME. Adhesive strips for the closure of surgical incisional sites: a systematic review and metaanalysis. Surg Innov. 2012;19:145-155. 